\title{
Assessing the Factor Influence on Patent Activity in Mining and Metallurgical Industry (e.g. Nano Products)
}

\author{
Svetlana A. Ulyanova ${ }^{\text {a* }}$, Veronika Yu. Ershova ${ }^{b}$, Lyudmila N. Korshunova ${ }^{c}$, Victoria S. Krasnobaeva ${ }^{d}$, \\ Svetlana M. Nuriyahmetova ${ }^{\mathrm{e}}$ \\ a, b, c, d,Department of Economics, Moscow State Institute of Steel and Alloys, Moscow 119049, Russia \\ ${ }^{\mathrm{e}}$ Department of Economics, Kazan Federal University, Kazan 420008, Russia
}

Article History: Received: 10 November 2020; Revised 12 January 2021 Accepted: 27 January 2021; Published online: 5 April 2021

\begin{abstract}
The creation of an intellectual property product with a vector of effective implementation into production predetermines the search for optimal proportions of interaction between scientific, industrial, and educational parameters. Scientific, industrial and educational types of organizations are proposed to be interpreted as objects of interrelated elements that have a direct impact on patent activity in the field of nano production. Additional emphasis was placed on the factors that arise in the process of commercialization of objects of intellectual activity and have a critical impact on the final results of the process. In this connection, it was proposed to introduce the concept of dysfunction (a dysfunctional indicator of the promotion of high technology products), considered as a factor-obstacle in the process of entering the market of intellectual property. It also introduces the definition of success (an indicator of the success of promoting science-intensive products), considered as a vector antonym of dysfunction, which is a defining tool to improve the effectiveness of the strategy for the commercialization of scientific developments and projects.

The paper defines the boundaries of the indicators of success and the dysfunctionality of the patent activity of high technology products using the example of nanomaterials. The indicators were evaluated for their compliance with the proposed criteria. This approach can be positioned as a way to identify and correct dysfunctional and successful factors that predetermine the effectiveness of patent activity of high technology products in the mining and metallurgical industry.

The article proposes a model for assessing the factors affecting patent activity in the mining and metallurgical complex, based on the division of factors into blocks of standard and specific purposes, based on the specifics of the nano object of the mining and metallurgical complex as a product on the market. The model includes scientific, educational, and industrial indices that have a direct impact on patenting activity in the field of nanomaterials and nanotechnology in the mining and metallurgical industry. The correspondence of scientific, production, and educational parameters was checked on the example of a scienceintensive product of the proposed model for increasing patent activity
\end{abstract}

Keywords: Patent activity, nanoproducts, market promotion, mining and metallurgical industry, marketing strategy.

\section{Introduction}

The marketing research of any product commercialization adheres to the following standard stages: analysis of external and internal factors, product market analysis, product promotion development, and promotion effectiveness evaluation [1]. However, given that nanomaterials are a rather specific science-intensive product, their path from idea to commercialization is saturated with an exclusive marketing approach. Embodying any idea into a product is undoubtedly a laborious process. The stages from the birth of the idea of creating an intellectual property object (i.e. patent, know-how, technologies, or software) and to their commercialization imply several stages and the possible synergy of various factors that are considered in this work.

\section{Objective}

The study's purpose is to identify success indicators and dysfunctionality of the patent activity processes of high technology products in the mining and metallurgical industry using the example of nanomaterials and nanotechnologies. The study feature is to determine the factors that are necessary to increase the effectiveness of intellectual property commercialization, in particular, nanomaterials in the mining and metallurgical industry.

The beginning of the nanotechnology era is characterized by several points: the peculiarities of substance properties while reducing its size; several recent discoveries in physics of low-dimensional structures; development of new technological methods for processing substances and the creation of new materials with unusual properties [2]. Nanoscience and nanotechnology are interdisciplinary and focus on nanoscale materials and processes [3]. In scientific sources, the 'Nano object' has two definitions. One of the definitions is technological, where nano-objects are characterized as objects with a certain size of from 1 to 100 nanometers in at least one dimension. Another definition has a physical component, where a nano-object acts from the position 
of an object with a reduced dimension (with $\mathrm{d} \leq \mathrm{d}^{*}$ in at least one dimension). As far as we know, there are no other definitions [4].

Thus, a nano-object feature can be recognized as its microminiaturization. Changing shapes and sizes at the nanometer level implies complex processes in creating a nano product, taking into account the understanding of science and technology unity. As a result of the transformation of nano-objects, a complete science-intensive product is obtained. These are nanomaterials or nanotechnology. All finished products of the knowledge-intensive market are the result of research and development. The final product comes out in the form of patents and production secrets (or know-how). Thus, the resulting scientific nano product is an object of intellectual property, that is, an object recognized as unique, not similar to everything that was created earlier. Today's close attention of researchers to nanostructures is caused by the tremendous progress in their synthesis [5]. In 2012, the Integrated Program for the Development of Biotechnology in the Russian Federation until 2020 was approved. It outlines the key areas of innovative development of the modern economy, including nanotechnology, which defines nanotechnology as the development and use of systems and technical devices in the nanoscale [6].

An indicator of the viability of a nano product is not just obtaining the material in nanoscale, but bringing it to the stage of practical application [7]. Nanomaterials and nanotechnology as a market science-intensive product must be developed and commercialized with the condition of economic feasibility. At present, interest in nanoobjects is growing rapidly, however, patent activity is in stagnation.

Based on Rosstat data [8] and the reference book of the Nano industry of Russia [9], we determine the growth rates of the nano industry product volume in Russian regions. Data corresponding to the period from 2015 to 2018 (Table 1).

Table 1 Nano products volume dynamics in regions of the Russian Federation from 2015 to 2018 (in \% comparing to last year).

\begin{tabular}{lllll}
\hline Regions of the Russian Federation & $\mathbf{2 0 1 5}$ & $\mathbf{2 0 1 6}$ & $\mathbf{2 0 1 7}$ & $\mathbf{2 0 1 8}$ \\
\hline RussianFederation & 113,6 & 124,1 & 102,1 & 127,2 \\
CentralFederalDistrict & 122,3 & 119,5 & 98,5 & 119,6 \\
Moscow & 130,7 & 112,9 & 84,1 & 116,8 \\
NorthwesternFederalDistrict & 134,8 & 99,0 & 99,2 & 104,3 \\
SouthernFederalDistrict & 134,6 & 134,6 & 74,4 & 143,2 \\
NorthCaucasianFederalDistrict & 125,0 & 102,5 & 84,7 & 32,8 \\
VolgaFederalDistrict & 96,8 & 157,81 & 104,5 & 144,4 \\
Uralfederaldistrict & 114,2 & 100,4 & 109,7 & 95,1 \\
SiberianFederalDistrict & 138,0 & 107,6 & 118,2 & 117,3 \\
CrimeanFederalDistrict & - & 31,4 & - & - \\
FarEasternFederalDistrict & - & - & - & - \\
\hline
\end{tabular}

Table 1 shows that in Russia in the period from 2017 to 2018 there was an increase of nano industry products. The peak is seen in the central federal district, the southern federal district and the city of Moscow. Let's consider the participants in the research and development process related to nanotechnologies, by type of organization for the period from 2015 to 2018 (Figure 1). 


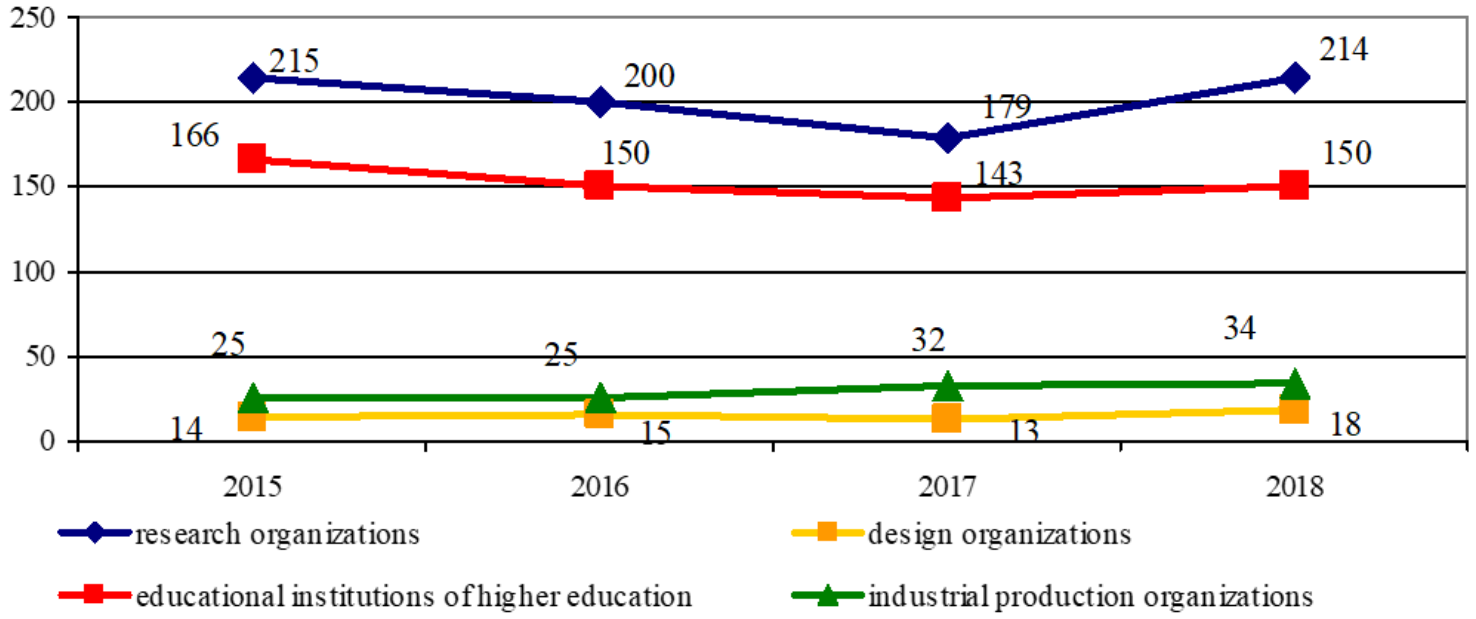

Figure 1 Participants in the research and development process related to nanotechnologies, by type of organization for the period from 2015 to 2018 , (units).

Thus, it is obvious that the main patent developments and research fall on the share of research organizations and educational institutions of higher education [20]. Based on the analysis data, it can be argued that the basic principle of implementing the concept of effective promotion of a science-intensive product is the unity of all three components: scientific, industrial, and educational spheres.

\section{Problem overview}

The viability study of nano-objects is possible in many ways. One way is to study patent activity around a single technology is through patent landscape analysis or patent mapping. The method essence is to process a large array of patent information with subsequent result visualization [10]. However, it is impossible to assess the object viability of intellectual activity without studying the factors influencing patent activity.

\section{Question theory}

The effective result implementation of intellectual work in the mining and metallurgical complex presupposes the consolidation of the following fundamental goals. For example, production necessity, unique technological methods of material processing, and improved properties of nano products.

The main strategic directions of intellectual activity commercialization, namely, nanotechnologies and nanomaterials in the mining and metallurgical industry:

1. Patenting and licensing the development of nano products in the mining and metallurgical complex;

2. Factor determination of influencing the patenting activity in the nano industry of mining and metallurgical complex;

3. Tool development of intellectual property in the mining and metallurgical industry.

Table 2 shows the leading organizations in metallurgy patenting [9].

Table 2Leading organizations in metallurgy patenting in 2018, (units).

: Name

Numberofpat ents (unit)

\section{Manufacturingcompanies}

Magnitogorsk Iron and Steel Works

Severstal

NovolipetskMetallurgicalPlant

Sinarskypipeplant

ChelyabinskPipe-RollingPlant

Plant named after V. A. Degtyarev

WestSiberianMetallurgicalPlant 
GorkyAutomobilePlant

9

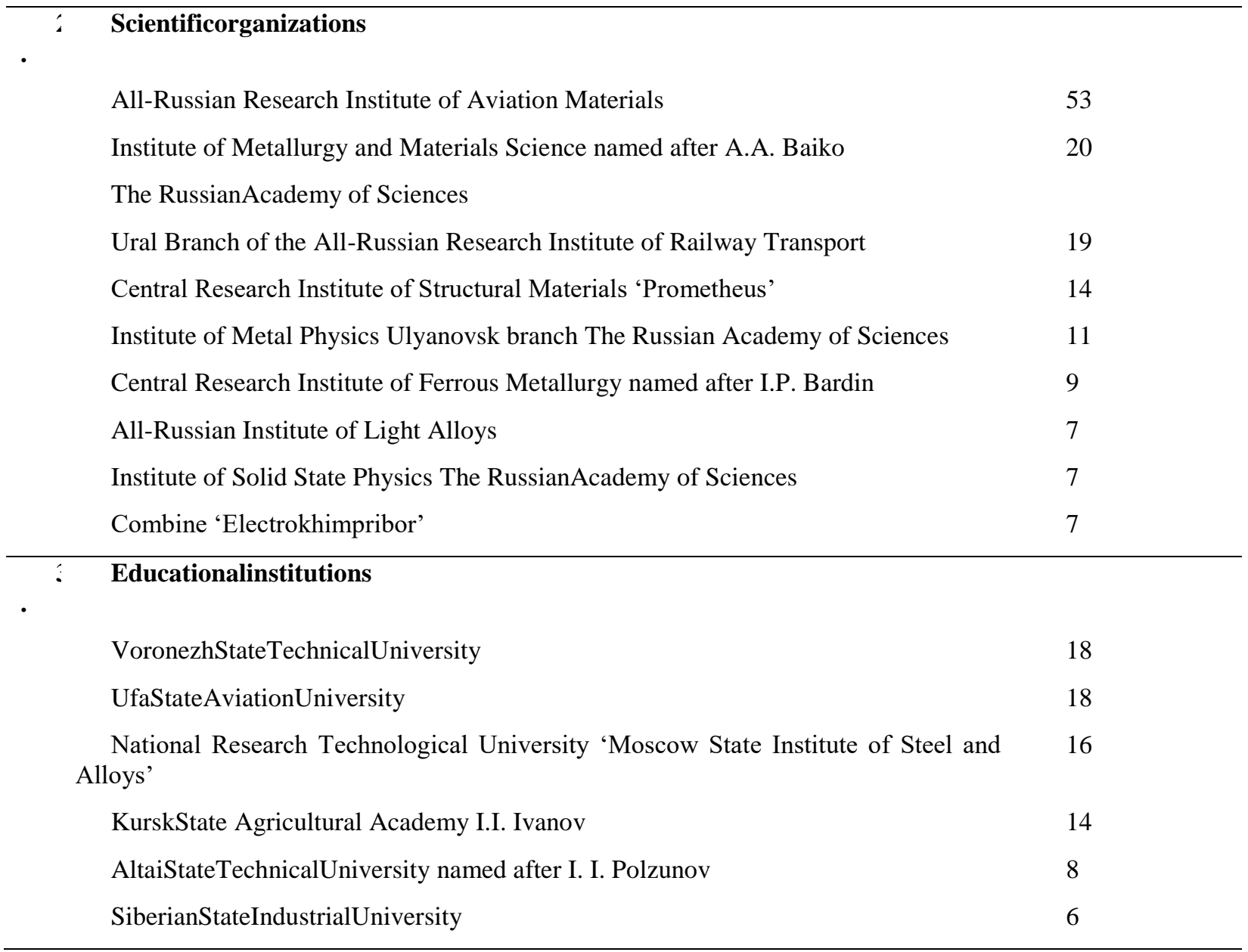

Table 2 shows that scientific organizations are implementing an active patent policy. Manufacturing companies rank second in patenting nano products. Voronezh State Technical University, National Research Technological University Moscow Institute of Steel and Alloys, Ufa State Aviation Technical University, and Kursk State Agricultural Academy [9] have the largest number of patents in the university sector. This once again gives rise to the identification of the main right holders of patents in the field of nanoproducts, the functioning of which is not always subject to favorable development trends [19].

The creation of an intellectual property product with a vector of effective implementation into production predetermines the search for optimal proportions of interaction between scientific, production, and educational parameters [18]. Scientific, industrial and educational types of organization can be interpreted as objects of interrelated elements that have a direct impact on patenting activity in the field of nano production. The production aspect of promoting intellectual property objects in the mining and metallurgical industry, if described from a quantitative point of view, suggests a favorable place for the implementation of scientific developments. The quality component is foreseen in the form of the effective development of mining and metallurgical production. At the same time, the implementation of industrial interests should be subordinated to scientific and educational priorities [11].

The educational essence of effective patenting of nanomaterials and nanotechnologies in the metallurgical complex is outlined in a concept that assumes a platform for the fruitful development of production and science.

The scientific aspect is the compass for educational and production elements. The difference in this model is based on the understanding of scientific research to obtain a balanced result. Great importance is attached to the direction of science since it can be the locomotive of the country's technological breakthrough [12].

\section{Methods}

A toolkit has been developed for assessing the factors affecting the efficiency of commercialization in the mining and metallurgical industry, taking into account the characteristics of a nano product [13]. It is proposed to 
consider the following stages of a strategic approach to increasing patent activity in the mining and metallurgical industry, taking into account the characteristics of a nano product as a commodity:

1. Factor classification into standard and specific for non-objects, taking into account their introduction into the mining and metallurgical complex;

2. Boundaries determination of success and dysfunction indicators by the method of mathematical expectation from each factor and its weight to determine the effectiveness of promoting high-tech products into production;

3. Model development for increasing patent activity in the mining and metallurgical industry, using the industry characteristics of a nano product, and taking into account the dysfunction and success parameters.

At the initial stage of this study, it is necessary to pay attention to the establishment of optimal criteria for the functioning of factors, which together determine the perspective and effectiveness of the result. Parameters of all factors of patent activity below the average or minimum allowable can be attributed to dysfunction. In other words, the obstacles that arise in the process of introducing objects of intellectual activity into the mining and metallurgical industry with a negative impact can be attributed to dysfunctional indicators. One of the main dysfunctional indicators is the lack of practices and methodologies to help integrate patent development into a company's production activities. The management of companies is not always prepared for the fact that their strategic and operational decisions will be based on patent policy. This dysfunction is due to the lack of knowledge and experience on how the availability of acquired patents can help in the field of strategic development and in determining the vector of investment. Additionally, legal gaps can be identified as a dysfunctional indicator on the way to advance patent policy in the field of nano products. In Russia, experts point out the lack of infrastructure for this industry. Despite the alignment of Russian legislation in the field of intellectual property following the provisions of the Agreement on Trade-Related Aspects of Intellectual Property Rights, abbreviated as TRIPS (reflected in Part 4 of the Civil Code of the Russia Federation), the protection of rights to innovative products is still greatly complicated [14].

Success rates in promoting high-tech products are seen as the antonym of dysfunction. The indicators of success include factors with effective impact.

Next, we will consider a model of interaction and interdependence of three subsystems, which will allow predicting the process of effective development of patent activity in the field of nanomaterials and nanotechnologies in the mining and metallurgical industry, taking into account the factors of dysfunction and success. The model includes scientific, educational, and industrial indices that have a point effect on the quantity and quality of patent activity in nanomaterials and nanotechnologies in the mining and metallurgical industry. The relationship is presented by the following inequality:

$$
I P P>I P O D>I P N R,
$$

$I P P$ - the industrial production index of the mining and metallurgical complex [15];

$I P O D$ - the participation index of educational institutions of higher professional education, high professional qualifications.

$I P N R$-thegrowth index of scientific developments in the industry.

The effective path of a nano product from an object of intellectual activity to an industrial design is characterized by the fulfillment of inequality (1), which can be interpreted as follows:

1. $I P P \rightarrow \max$, the index of industrial production should strive to the maximum since an increase in the extraction of ore and coal contributes to the development and growth of scientific research in the mining and metallurgical industry.

2. $I P O D>100$, this condition characterizes an increase in the number of scientific-educational and research centers based on higher educational institutions of higher education, high professional qualifications in the field of nano-objects.

3. IPNR $>100$, this condition characterizes the growth of scientific research, an increase in the number of intellectual property objects in mining and metallurgical production. It is necessary to recognize the dominant role of maximizing the index of the growth index of scientific developments in the industry to obtain a balanced result.

The proposed model will allow increasing patent activity, shortening the commercialization time of intellectual property objects, assessing the actual state of patent policy, and predicting expectations. The proposed method can be positioned as a way of analyzing and correcting dysfunctional indicators and turning them into indicators of success by choosing the right response tools. Success and processes dysfunctionality indicators affect changes in patent activity, it can be performed by defining a standard, which is used as the mathematical expectation of the 
sample. In our case, as a mathematical expectation, we take a multiplier of factors that make up the process of promoting patent nano production. In addition to the standard factors that are considered when promoting any product on the market, it is necessary to identify additional unique parameters for nano products that characterize the peculiarity of this type of nano product for the mining and metallurgical complex on the patenting market. The factors can be classified as standard and specific ones, and it is possible to assess the gradation of each factor by mathematical expectation.

The mathematical expectation calculation of each factor is made according to the following formula:

$x_{i} y_{i}=F$,

$F$ - expectation factor,

$x_{i}$ - possible factor value,

$y_{i}$ - event probability by $x_{i}$ factor.

The expectation from each standard and specific factor is determined. Using the ranking method and calculating the sum of the multipliers for each factor, we determine their dysfunction and success.

\section{Results}

Concerning the proposed methodology, let us consider the educational aspect in the promotion of patent activity on the example of the higher educational institution National Research Technological University 'Moscow State Institute of Steel and Alloys'.

Table 3 Patenting activity determinants expectation.

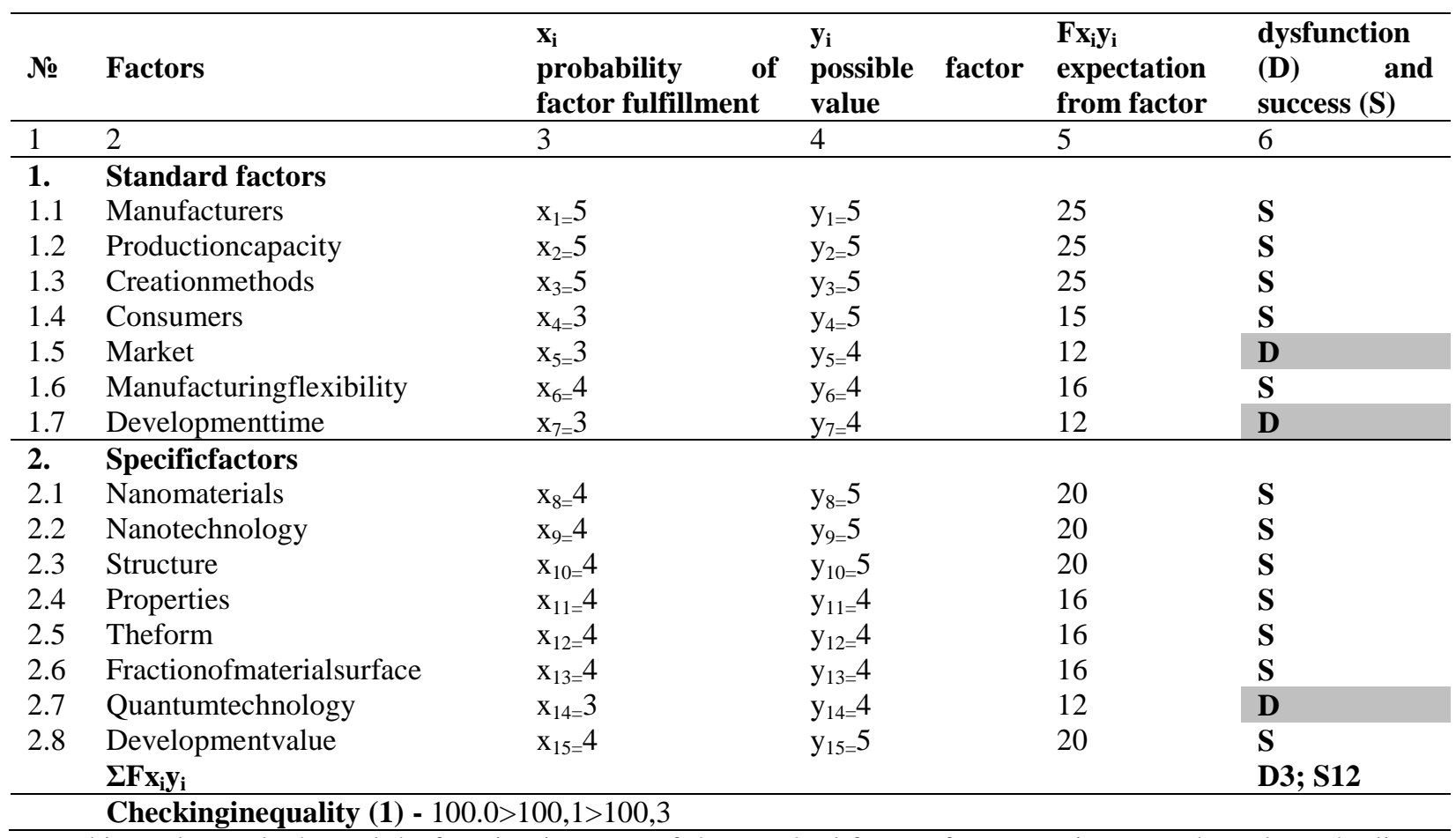

This study result showed dysfunction in terms of the standard factors for promoting a product along the lines of 'market' and 'production flexibility'. Dysfunction for the 'market' factor arose from a low factor score. The reason is the absence of a database on consumers of science-intensive developments and the lack of analysis of competitors. The production flexibility is characterized by the conditions for the introduction of a scienceintensive product into production [16]. The dysfunction of the factor is created as a result of company management uncertainty in patent policy effectiveness, which slows down the process of commercialization. Currently, a dysfunctional indicator has been identified for the quantum technology factor, however, shortly, it will become a success indicator. This is because the National Research Technological University 'Moscow State Institute of Steel and Alloys' and the Russian quantum center created a scientific collaboration 'Quantum Center of the National Research Technological University 'Moscow State Institute of Steel and Alloys', which included about 10 research laboratories and centers [21]. The combined potential will allow the 'Quantum Center National Research Technological University' Moscow State Institute of Steel and Alloys' to claim leadership positions among the world's leading research centers specializing in this area [17]. All other factors are in a state of success 
and exceed dysfunctional ones (D3> S12). Next, consider the fulfillment of inequality (1): 100.0> 100.1> 100.3. The inequality is fully satisfied, i.e. the extraction of minerals in the mining and metallurgical complex does not exceed the level of the previous year, and the scientific knowledge index excess has led to an increase in developments and the number of patents in the field of non-materials and nanotechnologies.

Thus, it is possible to recognize that the proposed method can be positioned as a way of finding and correcting dysfunctional areas and, as a result, determine the correct response tools.

\section{Conclusion}

As a result of the proposed toolkit for assessing the factors affecting the increase in the commercialization of nano-objects, it is assumed that dysfunctional indicators and indicators of success are identified in the form of a mathematical expectation from each factor. The results obtained make it possible to effectively control, correct, and analyze in dynamics the work of each factor separately, which will allow eliminating dysfunction and increasing the success of patent activity of nanoscience in the mining and metallurgical complex. The proposed approaches will improve the efficiency of patent policy in the nano industry. These recommendations allow you to calculate, analyze, control, and adjust the parameters of the factors quickly and, if necessary, strengthen the work on each factor separately.

\section{References}

MS Garifullina, SA Ashirova, YV Kabitova and SV Iudina. External economic relations of machinemanufacturing enterprises: Development potential. World Appl. Sci. J. 2013; 27 (13), p. 592-594.

DA Sokolov. Enterprise patent strategies(in Russian).NanoIndustry. 2014; 8(54), p. 64-77.

EA Goodilin, PS Weiss and YGogotsi. Nanotechnology Facets of the Periodic Table of Elements. ACS Nano. 2019; 13, 10, 10879-10886. https://doi.org/10.1021/acsnano.9b06998.

LB Piotrovsky and EA Katz. 'Nanotechnology', 'nanoscience' and 'nano objects': what does 'nano' mean?(in Russian).Ecology and life. 2012; 8. Available at: https://elementy.ru/nauchnopopulyarnaya_biblioteka/431265/Nanotekhnologiya_nanonauka_i_nanoobekty_chto_znachit_nano, accessed September 2020 .

MV Kovalenko,L Manna, A Cabot, Z Hens, DV Talapin, CR Kagan, VI Klimov, ALRogach, P Reiss, DJ Milliron, PGuyot-Sionnnest, GKonstantatos,WJ Parak,T Hyeon, BA Korgel,CB Murray, WHeiss. Prospects of Nanoscience with Nanocrystals. ACS Nano. 2015; 9, 1012-1057. https://doi.org/10.1021/nn506223h

TV Kuvyrchenkova. Development of nanotechnology: scientific breakthrough or threat(in Russian). Vestnik of Tver State University. 2020; 1 (61), 135-140.

GE Osland, ChR Taylor and ShZou. Selecting international modes of entry and expansion. Mark.Intell. Plan. $2001 ; 3,372$.

Federal State Statistics Service (Rosstat). Available at: www.gks.ru, accessed September 2020.

Russian Nanoindustry Directory. Available at: www.rusnano.com, accessed September 2020.

A Streletsky, V Zabavnikov, E Aslanov andD Kotlov. Patent landscape of the sphere of nanotechnology. Foresight(in Russian). The National Research University Journal of the Higher School of Economics.2015; 9 (3), 40-53.https://doi.org/10.17323/1995-459X.2015.3.40.53

V Filatov, N Zaitseva, A Larionova, E Rodina, V Eroshenko, N Vikhrova andO Takhumova. Socioenvironmental aspects of the waste recycling organization.EurAsian Journal of BioSciences. 2018; 12(2), $527-533$.

Y.G Smirnov, EV Skidanova, VB Kalugin and DE Voitsitsky. Monitoring of patenting of nanotechnologies in Russia(in Russian). Innovation. 2010; 3, 23-31.

GV Kruzhkova, YY Kostyukhin andIM Rozhkov. Choice procedure for expedient composition of electronic waste. Mining Informational and Analytical Bulletin. 2018; 9. https://doi.org/10.25018/0236-1493-2018-9-0$47-57$

Agreement on Trade-Related Aspects of Intellectual Property Rights. Document as amended by: International Protocol of December 6, 2005 (entered into force on September 22, 2017). The official Internet portal of legal information. Available at:www.pravo.gov.ru accessed September 2020.

AITatarkin. Comprehensive Program for the Development of Industry of the Sverdlovsk Region for the period up to 2020. Yekaterinburg, 2012, 464.

Sidorova E. The main factors and conditions determining the feasibility of production of high-tech products based on the potential of applied research organizations. In: Proceedings of 19thInternational Multidisciplinary Scientific GeoConference SGEM.Bulgaria, Albena, 30 June-6 July, 2019, p. 841848.https://doi.org/10.5593/sgem2019/5.3/S21.106

Official website of the National Research Technological University 'Moscow State Institute of Steel and Alloys'. Available at:https://misis.ru/university/about/,accessed September 2020. 
Sidorova E. Modern strategic decisions in the field of waste as a basis of development of circular economy and greening of industrial production. In: International Multidisciplinary Scientific Geo Conference Surveying Geology and Mining Ecology Management, SGEM, 2019.

Kondratyev V.V, Ivanov N.A, Rzhechitsky E.P and Sysoev I.A. Prospects for the application of nanotechnology and nanomaterials in the mining and metallurgical complex. Vestnik of Irkutsk National Research Technical University. 2010; 1 (41), 168-173.

Samarina V.P, Skufina T.P, Kostyukhin Y.Y, Savon.Relationship between iron ore deposits and spread of heavy metals in shallow water rivers: Natural and man-caused factors. CIS Iron and Steel Rev. 2020; 19, 7580.https://doi.org/10.17580/cisisr.2020.01.15

Agafonova II, Sidorova EY, Polezharova LV, Ryakhovsky DI, Kostina OV. Certain measures for tax regulation of industrial development and digital trade in Russia (National and international aspects). Journal of Advanced Research in Dynamical and Control Systems. 2020; 12(3). 1214-1222. 